\title{
Aqueous Oxidation of Zinc Sulfide in Hydrochloric Acid*
}

\author{
By Kôichi Arai**
}

\begin{abstract}
The aqueous oxidation of zine sulfide in diluted hydrochloric acid was carried out in order to obtain fundamental data on acidic leaching conditions.

Deaerated hydrochloric acid of $\mathrm{pH} 1 \sim 3$ and of $10^{-1} \sim 1 \mathrm{~mol} / \mathrm{L} \mathrm{Cl}^{-}$was used as acidic media. The amount of zinc sulfide powder suspended in the acidic solution was $10^{-2} \sim 10^{-1} \mathrm{~mol} / \mathrm{L}$. The solution was set under certain temperatures between $25^{\circ}$ $\sim 60^{\circ} \mathrm{C}$ and stirred at $600 \mathrm{rpm}$.

Results obtained from the experiment were as follows :

(1) The main dissolution reaction of zinc sulfide in acidic media was of the type of hydrogen sulfide formation and showed a parabolic behavior. The reaction was of diffusion control.

(2) The influence of $\mathrm{pH}$ to the dissolution rate of zinc sulfide was linear and the rate of dissolution was decreased with increasing value of $\mathrm{pH}$.

(3) The presence of chloride ion positively influenced the dissolution of zinc sulfide, especially at high temperature.

(4) The relation between the dissolution rate of zinc sulfide and the unit surface area of the ore powder suspended was almost linear. The rate was proportionally increased with increasing area of ore powder.

(5) The dissolution rate of zinc sulfide was large at the initial stage and then decreased with the lapse of time. The rate of dissolution of zinc sulfide was probably decreased with the coexistence of $\mathrm{Zn}^{2+}$ in the solution.

(Received January 31, 1970)
\end{abstract}

\section{Introduction}

The development of the direct leaching of sulfide ores is an important investigation in the field of hydrometallurgy. Since the leaching method of sulfide ores in the acidic solution under pressure was presented by Forward ${ }^{(1)(2)}$, extensive investigations have been carried out by several workers ${ }^{(3) \sim(18)}$.

As pointed out recently by Gerlach ${ }^{(19)}$, the theoretical treatment applicable widely to the aqueous oxidation of sulfide ores in acidic media is difficult at present.

But the reaction in aqueous solution can readily be understood thermodynamically by using the potential$\mathrm{pH}$ diagram proposed by Pourbaix ${ }^{(20)}$. The diagram was useful in explaining the mechanism of sulfiding corrosion $^{(21)}$ and of the reaction in extraction metal$\operatorname{lurg} y^{(22)(23)}$.

Though several works have been reported, many fundamental studies are needed to clarify the mechanism of hydrometallurgical reactions in acidic leaching conditions.

The author studied kinetics of the dissolution behavior

* This paper was originally published in Japanese in J. Japan Inst. Metals, 33 (1969), 965.

** Department of Metallurgy, Faculty of Engineering, Toyama University, Takaoka, Japan.

(1) F. A. Forward and H. Veltman : J. Metals, 11 (1959), 836.

(2) F.A. Forward and I. H. Warren : Metallurgical Reviews, 5 (1959), 137.

(3) Y. Umetsu and K. Tozawa: J. Min. Met. Inst. Japan, 80 (1964), 21.

(4) S. Okamura : ibid, 80(1964), 689

(5) Y. Hisamatu and N. Masuko : Electrochemical Soc. Japan, $31(1963), 771$.

(6) F. A. Forward and V. N. Mackiw : Trans. AIME, 203 (1955), 457.

(7) M. Itiziô, K. Ôsaki and K. Murayama : J. Min. Met. Inst. Japan, 83 (1967), 594.

(8) N. Masuko and Y. Hisamatu : ibid, 81 (1965), 1153.

(9) K. Azuma, S. Goto, S. Kameda and I. Asakura: ibid, 81(1965), 262. of zinc sulfide in hydrochloric acid in order to systematically explain the aqueous oxidation of sulfide ores in acidic media.

\section{Experimental}

\section{Materials}

The specimen was prepared from zinc sulfide of chemical grade and was screened to the size of 150 mesh. The chemical composition of the specimen was of nearly theoretical values ( $\mathrm{Zn}: 66.5 \mathrm{wt} \%, \mathrm{~S}: 33.45 \mathrm{wt} \%$ ).

The specimen was analyzed by $\mathrm{X}$-ray diffraction and its X-ray pattern showed both Sphalerite and Wurtzite. The specific surface area of zinc sulfide powder measured by the BET method was varied between $3.3 \times 10^{3}$ and $3.8 \times 10^{3} \mathrm{~cm}^{2} / \mathrm{g}$, and $3.5 \times 10^{3} \mathrm{~cm}^{2} / \mathrm{g}$ was adopted as its standard value. After drying at $40^{\circ} \mathrm{C}$, the specimen was used for the experiment. The zinc sulfide powder suspended in the test solution amounted to $10^{-2} \sim 10^{-1}$ $\mathrm{mol} / \mathrm{L}$.

(10) K. Azuma, S. Goto, S. Kameda and X. Asakura : ibid, 83(1967), 590.

(11) H. Majima and E. Peters : Trans. Met. Soc. AIME, 236(1966), 1409.

(12) T. R. Scott and N. F. Dyson: ibid, 242 (1968), 1815.

(13) A. Vizsolyi, H. Veltman and F. A. Forward: ibid, 227 (1963), 215.

(14) D. R. Mackay and J. Helpen : Trans. Met. Soc. AIME, 212 (1958), 301.

(15) K. J. Jackson and J. D. H. Strickland : ibid, 212 (1958), 373.

(16) J. Gerlach, H. Hähne and F. Pawlek : Z. Erz. Met., 18(1965), 73.

(17) J. Gerlach and F. Pawlek : ibid, 18 (1965), 509.

(18) J.Dahms, J. Gerlach and F. Pawlek : Z. Erz. Met., 20 (1967), 203.

(19) J. Gerlach : Metall, 16 (1962), 1171.

(20) M. Pourbaix : Allas of Electrochemical Equilibria in Aqueous Solutions, Pergamon Press, (1966), p. 545.

(21) J. Horvath and M. Novak : Corr. Sci.,4(1964), 159.

(22) Y. Hisamatu and N. Masuko : Metal, 29 (1959), 213.

(23) A. Yazawa : J. Japan Inst. Metals, 31(1967), 1158. 


\section{Preparation of the test solution}

The test solution with $\mathrm{pH} 1 \sim 3$ and $\mathrm{Cl}^{-}$concentration of $10^{-1} \sim 1 \mathrm{~mol} / \mathrm{L}$ was prepared from sodium chloride, hydrochloric acid and distilled water.

\section{Experimental procedure}

The apparatus used is shown in Fig. 1 . The reaction vessel of pyrex glass was of about 2 liter. The vessel was set in a thermostat and the content was stirred at a speed of $600 \mathrm{rpm}$ by the magnetic stirrer. After nitrogen gas was passed in the vessel in order to replace oxygen and a known weight of zinc sulfide ore was quickly added in the solution.

Nitrogen gas was passed at a speed of $200 \mathrm{~mL} / \mathrm{min}$ throughout whole experiments to remove hydrogen sulfide gas generated. At a certain interval, analytical samples were extracted from the vessel and analyzed by the EDTA titration method ${ }^{(24)}$

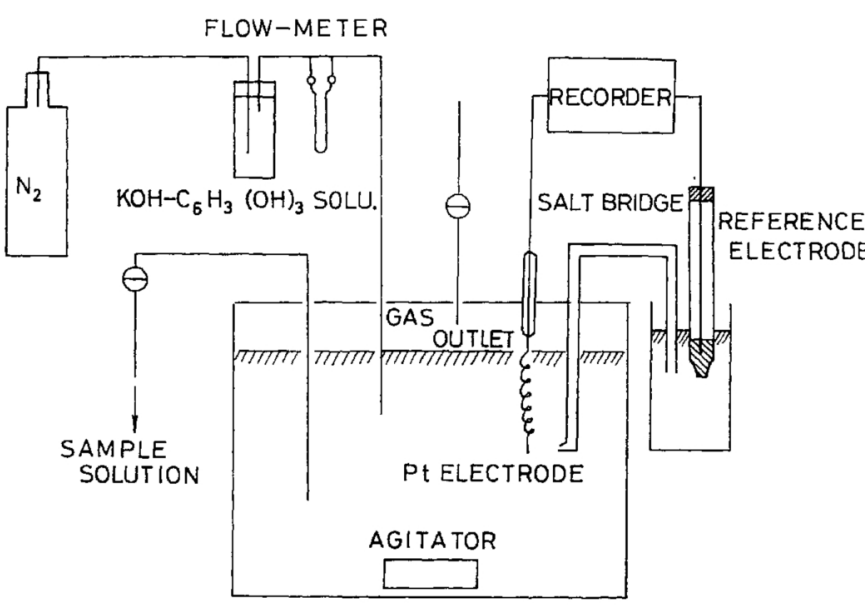

Fig. 1 Block diagram of the apparatus.

\section{Experimental Results}

\section{Kinetic dissolution behavior of zinc sulfide in acidic media}

According to equilibrium theory, the dissolution mechanism of zinc sulfide in acidic media is divided into the three reactions, i.e. $\mathrm{H}_{2} \mathrm{~S}$ formation type, $\mathrm{S}^{0}$ formation type and $\mathrm{SO}_{4}^{2-}$ formation type.

The diluted hydrochloric acid is better than sulfuric acid to obtain the data on the accurate dissolution behavior of zinc sulfide in acidic media.

In the preliminary test, extraction behaviors of zinc sulfide in diluted $\mathrm{HCl}$ and $\mathrm{H}_{2} \mathrm{SO}_{4}$ were compared with the result that the reaction types of zinc sulfide dissolution were the same in both acids. So the dissolution was carried out only in diluted $\mathrm{HCl}$. The effective factors on dissolution are considered to be $\mathrm{pH}$, the concentration of chloride ion, temperature, and the amount of zinc sulfide suspended in the solution.

The experiments were carried out to determine these factors.

The effect of $\mathrm{pH}$ on the dissolution is shown in Fig. 2 .

(24) K. Ueno : EDTA Titration, Nankôdo, (1960), p. 233
The dissolution of zinc sulfide in acidic media is large in the initial stage, and decreases with the lapse of time, showing a parabolic curve as a whole. The concentration of $\mathrm{Zn}^{2+}$ dissolved in the solution is affected by $\mathrm{pH}$ values and the extraction rate is decreased with increasing value of $\mathrm{pH}$.

In Fig. 3 an example of the influence of chloride ion concentration on the dissolution is shown. The extraction of $\mathrm{Zn}^{2+}$ are increased with increasing concentration of chloride ion in the solution at $60^{\circ} \mathrm{C}$, but extraction rates of $\mathrm{Zn}^{2+}$ are small in the range of high $\mathrm{pH}$ values, especially at low temperature.

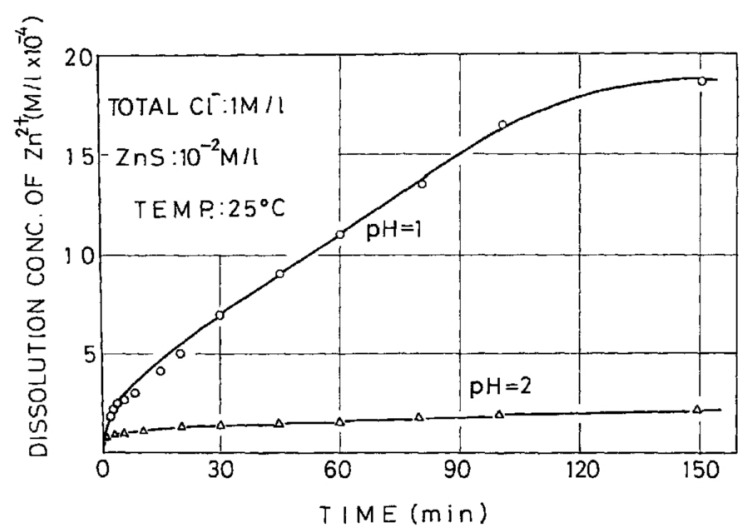

Fig. 2 Effect of $\mathrm{pH}$ on the dissolution of zinc sulfide in dilute $\mathrm{HCl}$ solution.

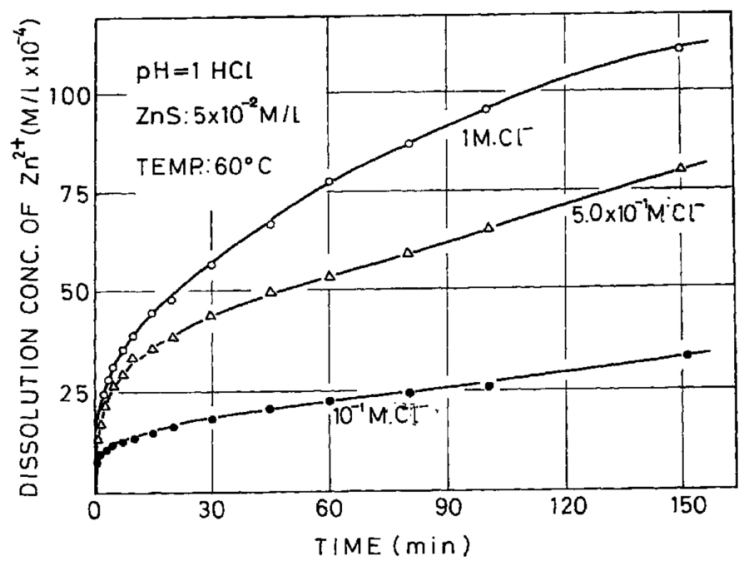

Fig. 3 Effect of $\mathrm{Cl}^{-}$ion on the dissolution of zinc sulfide in dilute $\mathrm{HCl}$ solution.

An example of the effect of temperature on the dissolution is shown in Fig. 4. The extraction amount of $\mathrm{Zn}^{2+}$ is increased proportionally with elevating temperature, but the influence of temperature is not marked at high $\mathrm{pH}$ values.

On the other hand, the dissolution of zinc sulfide was determined in the solution of $\mathrm{pH} 1$ at $60^{\circ} \mathrm{C}$ to obtain the influence of $\mathrm{Zn}^{2+}$ coexisting in the solution and the result is shown in Fig. 5. When $\mathrm{Zn}^{2+}$ coexists in the solution, the dissolution of zinc sulfide is inhibited in proportion to the amount of $\mathrm{Zn}^{2+}$ added in the solution.

An example of the influence of the amount of suspended zinc sulfide particle on the dissolution rate is shown in Fig. 6. The dissolution rate of zinc sulfide was 


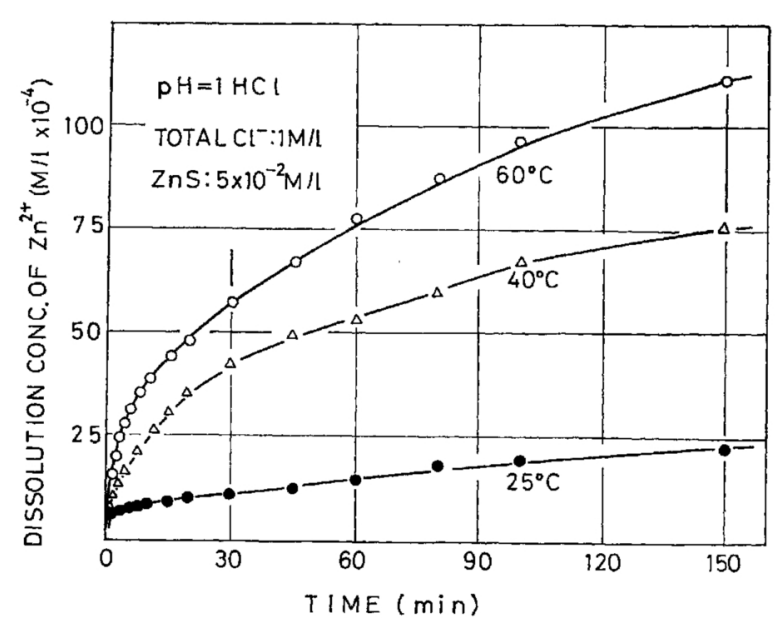

Fig. 4 Effect of temperature on the dissolution of zinc sulfide in dilute $\mathrm{FCl}$ solution.

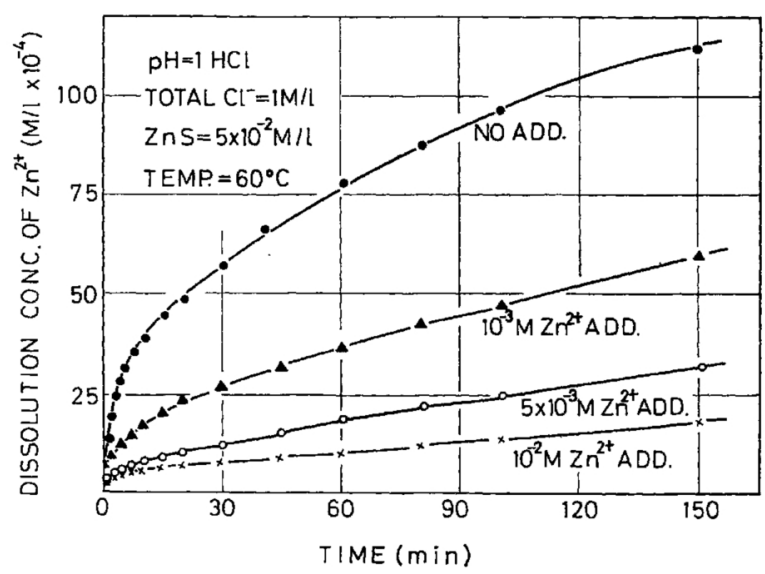

Fig. 5 Effect of additional $\mathrm{Zn}^{2+}$ ion on the dissolution of zinc sulfide in dilute $\mathrm{HCl}$ solution.

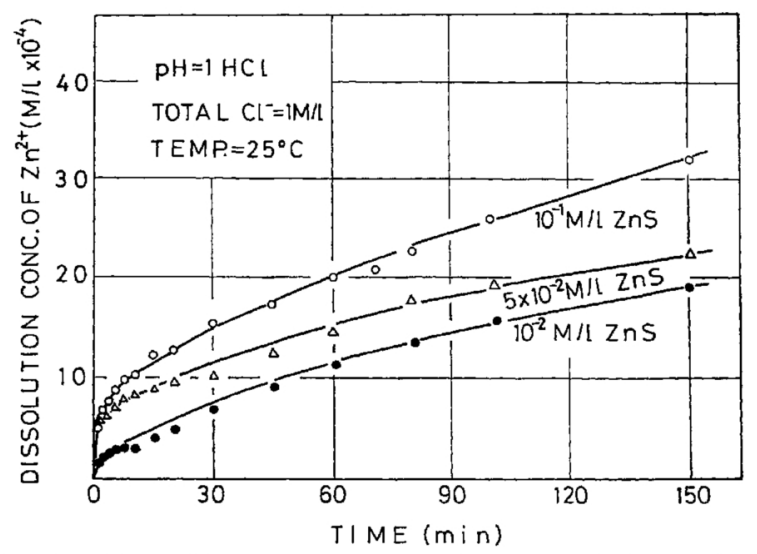

Fig. 6 Effect of the amount of suspended zinc sulfide on the dissolution in dilute $\mathrm{HCl}$ solution.

increased linearly with increasing specific surface area of ore particle in the solution.

\section{Behavior of sulfur}

Both sulfate and sulfur formations of zinc sulfide in acidic media were analyzed by measurements of barium sulfate weight and $\mathrm{X}$-ray diffraction. But, $\mathrm{SO}_{4}^{2-}$ in the solution and the $\mathrm{S}^{0}$ formation in the precipitate could not be seen. A small quantity of amorphous sulfur was only found in the precipitate by extraction with pyridin.

\section{Equilibrium potential of the platinum electrode in acidic solution saturated with hydrogen sulfide gas}

In the above experiments, the dissolution of zinc sulfide in acidic leaching solution was measured by volumetric analysis and X-ray diffraction and the main reaction was concluded to be of the $\mathrm{H}_{2} \mathrm{~S}$ formation type in the experimental conditions. The equilibrium potential of the platinum electrode immersed in the acidic solution containing zinc sulfide and saturated with hydrogen sulfide gas was determined according to reference (5).

As shown in Fig. 7 the $\mathrm{pH}$ dependence of potentials $(\mathrm{d} E / \mathrm{dpH})$ was $120 \mathrm{mV}$ in the region of $\mathrm{pH} 0 \sim 1.5$ and $58 \mathrm{mV}$ in $\mathrm{pH} 1.5 \sim 4$.

In the low $\mathrm{pH}$ solutions the $\mathrm{pH}$ dependence of potentials was twice greater than that in the high $\mathrm{pH}$ solutions, but both solutions showed a similar redox potential of the $\mathrm{S} / \mathrm{H}_{2} \mathrm{~S}$ system.

On the other hand, the electrode potential of the platinum electrode in acidic solution containing zinc sulfide and saturated hydrogen sulfide gas showed a noble potential value at the initial stage and then shifted rapidly to the basic potential side. But the potential showed similar values in redox potential of the $\mathrm{S} / \mathrm{H}_{2} \mathrm{~S}$ system and was not affected by the amount of zinc sulfide suspended.

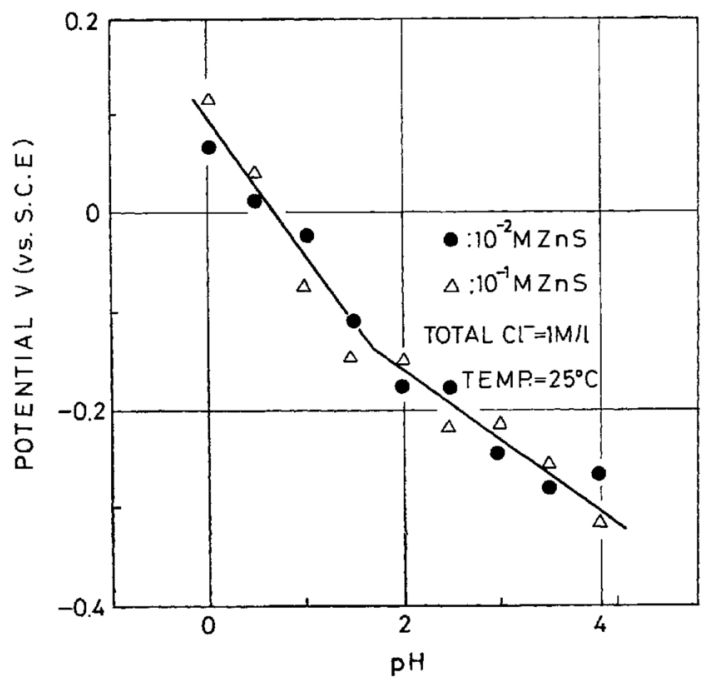

Fig. 7 Effect of additional zinc sulfide on the equilibrium potential of the Pt electrode in acidic solution containing $1 \mathrm{M} \mathrm{CI}{ }^{-}$and saturated with $\mathrm{H}_{2} \mathrm{~S}$.

\section{Discussion}

In the acidic solution with no oxygen, the dissolution of zinc sulfide was considered to be the reaction type of hydrogen sulfide formation from the experiments ( $1 \sim 3$ ) at high temperature, but according to equilibrium theory, this type of reaction could be discussed by the potential$\mathrm{pH}$ diagram of the $\mathrm{Zn}-\mathrm{S}-\mathrm{H}_{2} \mathrm{O}$ system. This diagram was made out on the basis of the calculation of Latimer's data ${ }^{(25)}$, as shown in Fig. 8. This coincided to the experimental results that in such high solubility sulfides

(25) W. M. Latimer : Oxidation Potentials, Second Ed., PrenticeHall, Inc., (1952), p. 168. 


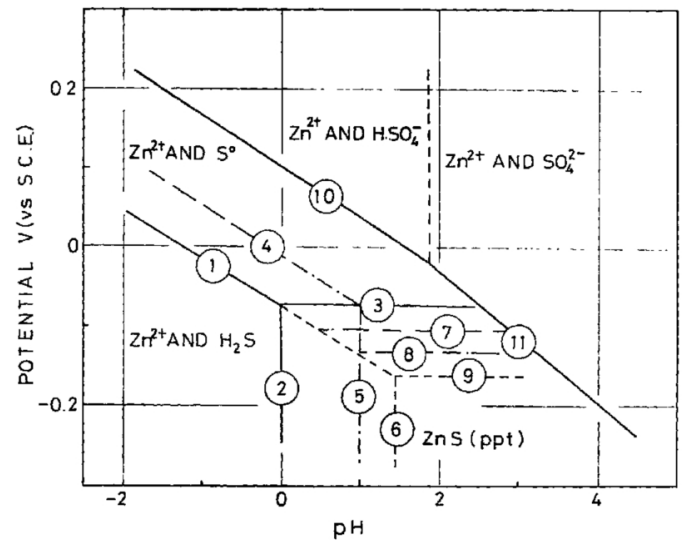

Fig. 8 Potential-pH diagram of $\mathrm{Zn}-\mathrm{S}-\mathrm{H}_{2} \mathrm{O}$ system at $25 \mathrm{C}^{\circ}$.

(1) $\left(\mathrm{H}_{2} \mathrm{~S}\right)=10^{-1}\left(P_{\mathrm{H}_{2} \mathrm{~S}}=1 \mathrm{~atm}\right)$ (2) $\left(\mathrm{H}_{2} \mathrm{~S}\right)=10^{-1},\left(\mathrm{Zn}^{2+}\right)=1$

(3) $\left(\mathrm{Zn}^{2+}\right)=1$ (4) $\left(\mathrm{H}_{2} \mathrm{~S}\right)=10^{-3}$ (5) $\left(\mathrm{H}_{2} \mathrm{~S}\right)=10^{-3},\left(\mathrm{Zn}^{2+}\right)=1$

(6) $\left(\mathrm{H}_{2} \mathrm{~S}\right)=10^{-1},\left(\mathrm{Zn}^{2+}\right)=10^{-3} \quad$ (7) $\left(\mathrm{Zn}^{2+}\right)=10^{-1}$ (8) $\left(\mathrm{Zn}^{2+}\right)$

$=10^{-2}$ (9) $\left(\mathrm{Zn}^{2+}\right)=10^{-3} \quad$ (10) $\left(\mathrm{HSO}_{4}^{-}\right)=1$ (11) $\left(\mathrm{SO}_{4}^{2-}\right)=1$

as zinc sulfide, the reaction type of hydrogen sulfide formation took place predominantly in the deaerated solution of low $\mathrm{pH}$ and at high temperature.

The extraction behavior of zinc sulfide under an acidic leaching condition can be expected according to equilibrium theory, providing useful information in the field of hydrometallurgy from the kinetic point of view. Kinetic analysis of the extraction of zinc sulfide was carried out as follows. As shown in Figs. 2 6, the dissolution of zinc sulfide is large in the first step and the concentration of $\mathrm{Zn}^{2+}$ dissolved increases with time. The reaction is considered to be a mono-molecular reaction, and the data were treated by linear law.

As shown in Fig. 9, the concentration of zinc sulfide in the solution decreases with time and the dissolution rate of zinc sulfide increases with temperature.

An Arrhenius plot of the rate constant $k$ with temperature is shown in Fig.10. The apparent activation energy was obtained to be $5.64 \times 10^{3} \mathrm{cal} / \mathrm{mol}$ and this value corresponds to the diffusion control of ion in the solution.

In Fig. 11, a parabolic plot of the dissolution of zinc sulfide is shown as an example. The kinetics of extraction of zinc sulfide is essentially governed by the diffusion of ion in the solution and is thus of the form,

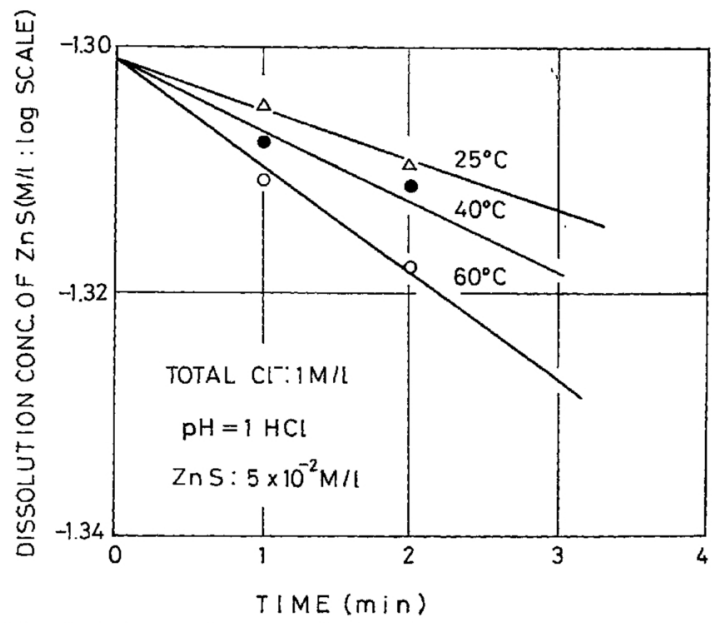

Fig. 9 Relation between the dissolution of $\mathrm{ZnS}$ and time.

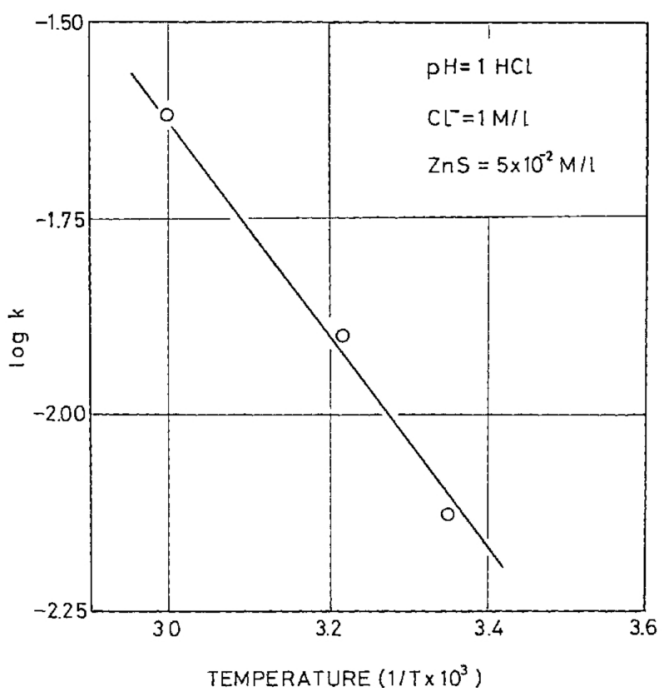

Fig. 10 Relation between the dissolution rate constant of $\mathrm{ZnS}$ and temperature of dilute $\mathrm{HCl}$ solution.

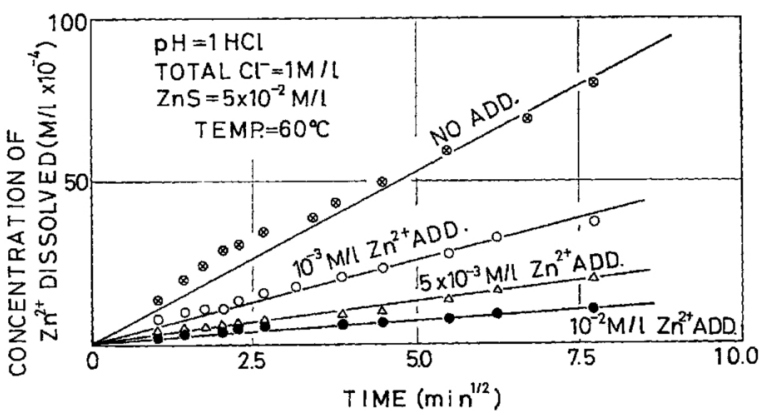

Fig. 11 Parabolic plot of the dissolution of $\mathrm{ZnS}$ in dilute $\mathrm{HCl}$ solution.

$$
N s=k_{1} \times t^{1 / 2}
$$

where $N s$ is moles of $\mathrm{Zn}^{2+}$ dissolved, $k_{1}$ a constant, and $t$ the time in minute.

By differentiation of (1),

$$
\mathrm{d} N s / \mathrm{d} t=\frac{1}{2} k_{1} \times t^{-1 / 2} .
$$

If the constant $\left(\frac{1}{2} k_{1}\right)$ is replaced by $k_{2}$, eq. (2) is followingly

$$
\mathrm{d} N s / \mathrm{d} t=k_{2} \times t^{-1 / 2}
$$

from (3) the rate constant $k_{2}$ can be calculated. If $N s / t^{1 / 2}$ $=r_{0}$,

$$
r_{0} \propto k_{2} \text {. }
$$

Hence, the parameter $r_{0}$ can be taken instead of $k_{2}$, and then several effective factors on the kinetics of the dissolution behavior of zinc sulfide in the acidic leaching condition are discussed.

The effect of acidity on the kinetic dissoultion behavior of zinc sulfide is shown in Fig. 12, which can be expressed by the equation,

$$
\log T_{0}=\alpha \log u \mathrm{H}^{+}+\beta
$$

where $\alpha$ and $\beta$ are constants and $a$ is the activity of hydrogen ion.

The effect of temperature on the constant $(\alpha)$ is rather 


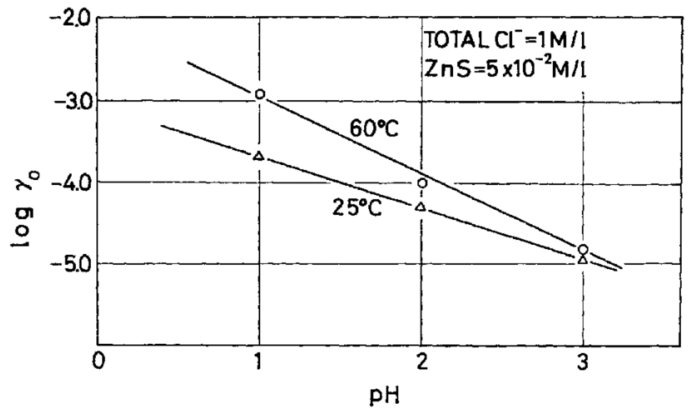

Fig. 12 Relation between the $\gamma_{0}$ and the $\mathrm{pH}$ of dilute $\mathrm{HCl}$ solution containing $1 \mathrm{M} \mathrm{Cl}^{-}$.

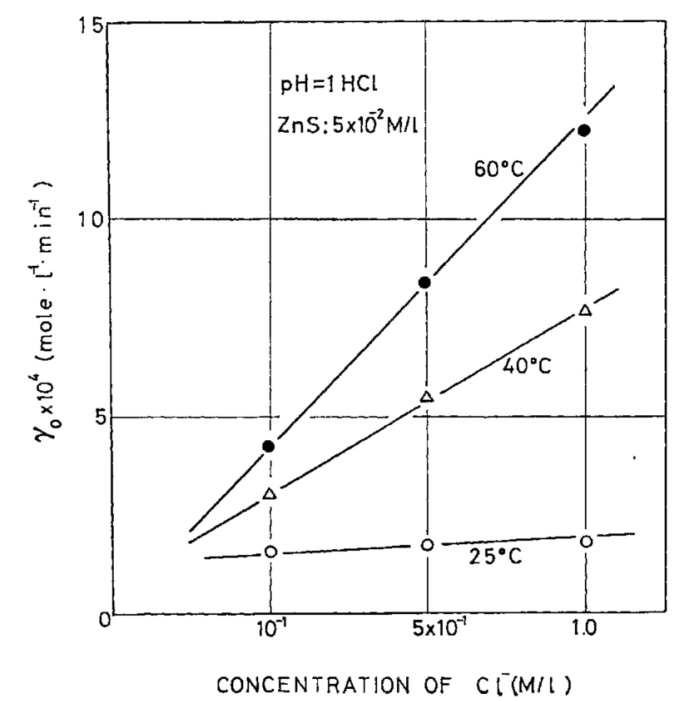

Fig. 13 Relation between $\gamma_{0}$ and the concentration of $\mathrm{Cl}^{-}$in dilute solution of $\mathrm{pH}=1$.

small at low temperature but increased with temperature. The value of $\alpha$ is about 1 at $60^{\circ} \mathrm{C}$. As shown in Fig. 13, the correlation between $r_{0}$ and the concentration of chloride ion in diluted solution is linear and the value of $r_{0}$ is increased proportionally with increasing concentration of chloride ion in the solution.

But the dependence of $r_{0}$ on chloride ion is varied with temperature, being relatively small at low temperature and large at high temperature.

The effect of chloride on the rate is increased with elevating temperature.

The relations among the specific surface area of ore particles, the extraction rate and the suspended state of ore in the solution are shown in Fig. 14, and the following equation is obtained:

$$
\log r_{0}=\delta \cdot A / V+\varepsilon,
$$

where $A$ is the specific area of ore particle, $V$ the volume of leaching solution, and $\delta$ and $\varepsilon$ are constants. The extraction rate of zinc sulfide is increased with increasing specific area of ore in unit concentration of the acid and the reaction is considered a typical hetrogeneous process which shows a strong dependence on the surface of zinc sulfide.

On the other hand, the effect of addition of $\mathrm{Zn}^{2+}$ on the extraction rate is shown in Fig. 15. The reaction rate is decreased with increasing addition of $\mathrm{Zn}^{2+}$ in the

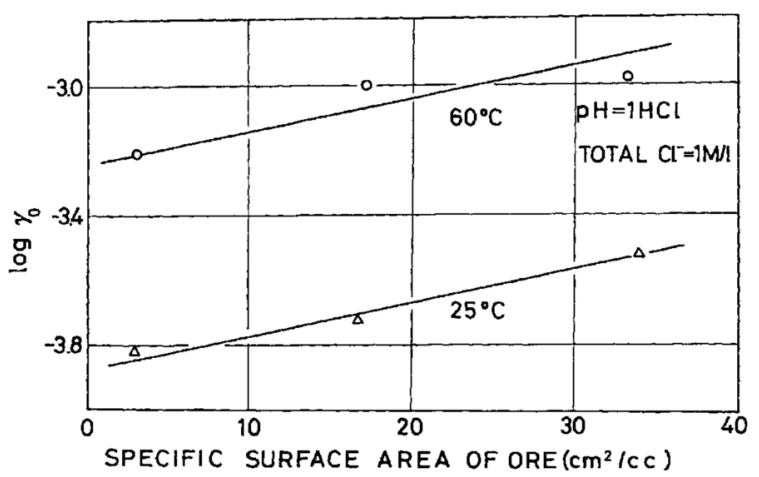

Fig. 14 Relation between $\log \gamma_{0}$ and the surface area of ore in dilute $\mathrm{HCl}$ solution of $\mathrm{pH}=1$.

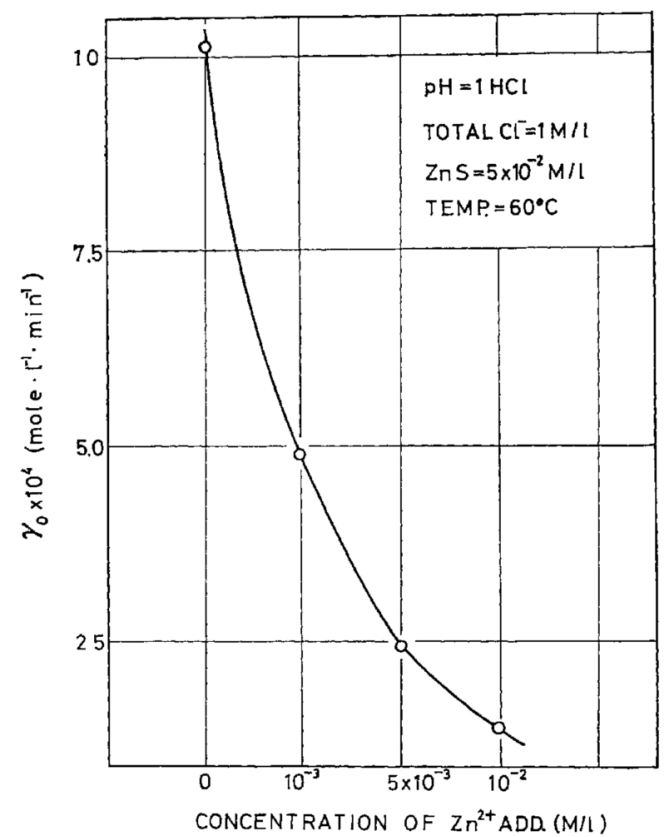

Fig. 15 Relation between the $\gamma_{0}$ and the concentration of $\mathrm{Zn}^{2+}$ added in dilute $\mathrm{HCl}$ solution of $\mathrm{pH}=1$ at $60^{\circ} \mathrm{C}$.

solution, and the dissolution of zinc sulfide is suppressed.

One of the reasons for the decreasing rate with time is considered to be due to the inhibition of dissolution with increasing concentration of $\mathrm{Zn}^{2+}$ coexisting in the solution.

The kinetics of the dissolution reaction of zinc sulfide is discussed according to rate theory and the dissolution of zinc sulfide under the condition measured is of a type of hydrogen sulfide evolution as expressed by

$$
\mathrm{ZnS}+2 \mathrm{H}^{+} \rightarrow \mathrm{Zn}^{2+}+\mathrm{H}_{2} \mathrm{~S} \text { (aq.) . }
$$

From the results determined, factors of the extraction reaction of zinc sulfide are considered as diffusion control of ion in the solution or transport control. The fact that the reaction is affected by stirring velocity should be understood. A similar conclusion on the kinetic study on extraction of pyrite in the acidic leaching condition has been made elsewhere ${ }^{(26)}$.

On the other hand, the equilibrium potential of the platinum electrode immersed in the zinc sulfide suspended

(26) M. I Sherman and J.D. H. Strickland : Trans. AIME, 209 (1957), 1386 
solution shows a value close to the potential of the $\mathrm{S} / \mathrm{H}_{2} \mathrm{~S}$ system in case of the existence of hydrogen sulfide and the main extraction reaction of zinc sulfide is considered to obey eq. (7).

The reason for the anion effect to increase the dissolution rate of zinc sulfide is considered as the activation of the interface of zinc sulfide by chloride ion.

\section{Conclusion}

Factors which affect the dissolution of zinc sulfide in hydrochloric acid are analyzed from a kinetic point of view and the results obtained are concluded as follows:

(1) The main dissolution reaction of zinc sulfide in the acidic solution is of a type of hydrogen sulfide formation and shows a parabolic behavior. The reaction is of diffusion control.

(2) The effect of $\mathrm{pH}$ on the dissolution rate of zinc sulfide is linear and the rate of dissolution decreases with increasing value of $\mathrm{pH}$.

(3) The presence of chloride ion positively affects the extraction of zinc sulfide, especially at high temperature.

(4) The relation between the extraction rate of zinc sulfide and the surface area of ore particles suspended in the solution is linear and the rate increases proportionally with increasing area of the ore.

(5) The dissolution rate of zinc sulfide is large at the first stage and decreases with time. The rate is decreased under the coexistence of $\mathrm{Zn}^{2+}$ in the solution. 